\title{
Competitiveness and environmental policy: a failed marriage?
}

\section{Irina Tanasescu'}

\section{Introduction}

Since the mid-1990s, the traditional Community method of policy-making and the resulting command-and-control legislation has been challenged as viable means to regulate markets. The emphasis on subsidiarity and on the "better regulation" agenda contributed to weakening the political support for centralized, top-down EU legislative action and encouraged wider recourse to more cooperative modes of multi-level governance. This trend was further reinforced by the debates following the adoption of the Lisbon strategy. In this context, competitiveness entails working with markets which, in turn, implies that measures that could be detrimental to the competitiveness of producers and could give rise to contestation are avoided. At the same time, the adoption of the EU Sustainable Development Strategy and its addition as the third, environmental, pillar to Lisbon meant that environmental policy-making would be influenced by the overall Lisbon goals. In order to achieve support and cooperation from actors in the markets, policy makers must convince actors in the market of the benefits and competitive rewards of operating in an environmentally sound manner. This concern for competitiveness gave rise to a particular market-oriented approach to EU environmental policy, which seeks to work 'with' rather than 'against' markets to achieve environmental improvements.

The emphasis on competitiveness also has an impact on the policy instruments selected for environmental purposes. Working with markets requires voluntary compliance and cooperation and has thus strengthened the shift to deregulation. The latter entails the replacement of topdown, traditional regulatory approaches with an increased use of voluntary instruments such as voluntary environmental agreements (VEAs), the Environmental Management and Audit System (EMAS) or the EU Eco-labeling scheme. These kinds of instrument have gained salience over the last years to such an extent that new, encompassing EU-level framework policies such as the Integrated Product Policy (IPP) (2003) or the recent Directive on the Eco-Design of Energy Using Products (EuP) (2005) rely heavily on voluntary instruments or producer initiatives.

The first goal of this article is to provide an analysis of the current organization, functioning and up-take of the three instruments mentioned (e.g. EU eco-label, EMAS and VEAs). It will be based on existing official documents and academic literature, as well as on a series of interviews carried out between March and June 2005 with public authorities, stakeholders and NGOs (all both at the EU and at the Belgian national level) involved in the day-to-day implementation or follow-up of these tools. 
Since the voluntary instruments are increasingly mixed and enshrined in different EU environmental policy initiatives I also seek to examine their role and their likelihood of success in the context of IPP and as implementation tools for EU environmental policy in general. The stronger accent on IPP is motivated by the fact that the policy has been in the implementation stage since 2003, while in the case of the EuP directive not much happened since its adoption last year.

The move towards voluntary instruments seems to be accompanied by a move towards increased policy ambiguity. Policy initiatives convey general principles and goals but leave much to be specified by private actors coming forth voluntarily to provide content and substance to the policy. Because much of the policy content remains to be determined at the stage when the voluntary instruments are to be adopted and executed, the policy takes the shape as a "natural experiment". Policy makers are unclear as to the precise market response, the measures and precise goals of the policy initiative. Therefore, carrying out the policy takes shape throughout many different implementation experiments and becomes an exercise of "learn as you go". Richard Matland coined this form of policy execution in a context of high ambiguity and low conflict as "experimental implementation" (Matland, 1995). In the experimental design, policy measures actually included few unambiguous decisions. Decisions are no longer taken at the policy design stage, but are shifted towards the implementation stage, which in turn is entrusted to private stakeholders adopting voluntary instruments. One example is IPP, for which the Communication of the Commission only provides a framework and a set of tools - all voluntary - without clear targets or quantified objectives. The third goal of the paper regards the question whether this "we'll see what we have to do when we'll do it, in case we feel like it" approach can work for delivering on environmental objectives?

The article will proceed as follows: after a brief analysis of the relationship between Lisbon and the EU Sustainable Development Strategy, the analysis of the three voluntary instruments selected will follow, keeping in mind the three objectives states above. The analysis will conclude with an assessment of the efficiency of these instruments, using "experimental implementation" as the main analytical tool.

\section{Lisbon and sustainable development}

The relationship between the Lisbon strategy and the Sustainable Development Strategy (SDS) has been, from the outset, an ambiguous one. Even if the mandate to elaborate a SDS, given by the Helsinki European Council to the Commission in December 1999, clearly asked for "a strategy dovetailing policies for economically, socially and ecologically sustainable development" (Presidency Conclusions, 1999), the fact that the Lisbon goals were formulated before the SDS came into being translated into a split of these objectives between two different strategies. Thus, back in 2000, both the Commission's contribution to the Special European Council in Lisbon and the European Council itself focused exclusively on economic and social issues, with no mention of the environmental dimension. One year later, the European Council convened in Göteburg to adopt the SDS: a concept traditionally understood as a balance between economic, social and environmental dimensions. Nevertheless, the first two dimensions had already been covered by Lisbon, therefore narrowing the scope of the SDS that, instead of building equally on the three pillars (economic, social and environmental), only "adds a third, environmental dimension to the Lisbon Strategy" (Presidency Conclusions, 2001). Thus, the two strategies were supposed to be complimentary, with a big question mark regarding the creation of synergies between them and the identity of the "guiding" Strategy: how would the integration between the two be achieved in practice? Would the economic and social objectives of Lisbon take primacy over the environmental concerns of the SDS or would environmental issues condition the development of economic and social policies? The answer to the first question seemed to be offered by the Spring European Council meetings that, as of 2002, undertook the annual review process of both strategies in an integrated manner. Thus, for instance, the 2004 Spring European Council Conclusions mentions that "the Lisbon Agenda is based on a consistent approach: between the actions of the Union and 
those of the Member States, and also between the different areas of policy - economic, social and environmental" (Presidency Conclusions, 2004), which would signal a full integration of the SDS into the Lisbon Strategy, at least at a rhetoric level. In practice, it is hard to understand to what extent the environmental dimension of Lisbon is taken seriously into account, given the fact that Lisbon itself is concerned with economic and social measures targeted at making the EU "the fastest growing knowledge-based economy in the world". Moreover, the 2005 spring report is almost entirely dedicated to the economic side of the Lisbon agenda, only paying lip-service to sustainable development and begging the question whether the environmental dimension has simply been dropped on the way. Not to mention that the EU has a "competitiveness" Council but no "sustainable development" Council (matched by the fact that no member state has a "sustainable development" minister) and that within the Commission there is a "competitiveness" Commissioners' group but no "sustainable development" equivalent.

The recent re-launch of both strategies could have been a good moment to clarify the relationship between the two, but for the moment this opportunity seems to have been missed. The first thing to notice here is that instead of a joint review process, the Commission chose to treat them separately and, once again, Lisbon came first. Despite Wim Kok's recommendations in the mid-term review of Lisbon, which included a series of environmentally-oriented measures, the Commission chose to prioritize economic and social interests for the time being, with the renewed Lisbon strategy focusing on growth and jobs. This is very much in line with the position the President of the Commission expressed in front of the European Parliament. Barroso compared sustainable development with having three children, loving all three, but focusing on the sick child (the economy) until he gets well, a clear indication of economic concerns being prioritized over environmental ones. On the other hand, the same Commission states, in its 2005 Communication on guiding principles for sustainable development, that "the renewed Lisbon Agenda is an essential component of the overarching objective of sustainable development, allowing us to use the motor of a more dynamic economy to fuel our wider social and environmental ambition". Moreover, the Communication on the renewed Lisbon Strategy itself uses similar language, declaring that "the Lisbon Strategy is an essential component of the overarching objective of sustainable development set out in the Treaty" (Commission, 2005). Thus. we have the Commission arguing, on the one hand, that growth and competitiveness are the main priority, and that environmental concerns can wait, and, on the other hand, making sustainable development the "overarching" strategy. While these contradictory messages leave one wondering about which strategy is, theoretically speaking, the overarching one, in practical terms no clues are provided as to the integration of the two. Until 2005 the European Spring Council dealt with the review of both on a joint basis. Thereafter, the SDS and Lisbon will no longer be assessed together. Sustainable development will be monitored every two years by the December European Council (starting in 2007), while Lisbon will continue to be dealt with on a yearly basis by the Spring European Council. This decoupling might, in practice, lead to even less integration between the two. Where integration might occur is via the Impact Assessment (IA) mechanism, that should ideally offer a balanced account of the likely economy, social and environmental impacts of all major policy initiatives. Environmental NGOs are skeptical as to the use of IAs, given that until now "this instrument was not balanced at all, giving more concrete attention to short term business impacts and inadequate attention to the other two dimensions" (EEB, 2005). Nevertheless, it could potentially serve as a bridge between the two strategies if applied correctly and in a balanced manner.

To sum up, the relationship between the SDS and Lisbon is extremely ambiguous and, for the moment, the focus seems to be moving further and further away from sustainable development into the direction of growth and competitiveness. The Commission is paying lip-service to sustainable development by calling it the "overarching" objective for Lisbon. If this were indeed the case, then it would have made much more sense to review the "overarching" sustainable development strategy before, or at the same as Lisbon, in order to have the economic and social policy proposals of the latter reshaped in light of the former. The inconsistencies between the two could originate in the differences in scope and operational level that existed from the outset between them, as identified in a Report commissioned by the Secretariat General of the Commission in 2004. 
"The Lisbon strategy thus focuses first and foremost on economic growth and social cohesion and sets time-bound and quantitative targets in these areas while the Gothenburg strategy is a much broader and long-termed strategy" (Commission, 2004). Nevertheless, the fact that this imbalance was not only not addressed in the review of both strategies, but was further accentuated in the decoupling of their periodic assessment, is an indication of the lack of political will to make sustainable development the real priority.

\section{Voluntary instruments in EU environmental policy-making}

Even if the debates around better regulation have been present in EU-level and national debates since the mid-80's (at the time, regulatory simplification was seen as a precondition for the completion of the single market), they received increased attention and were dealt with in a more systematic way in the context of the Lisbon goals. It was the Lisbon European Council that asked the Commission and the Member States "to set out by 2001 a strategy for further co-ordinated action to simplify the regulatory environment, including the performance of public administration, at both national and Community level" (Council, 2000). Better regulation is clearly part of the effort the EU needs to make to become "the most competitive economy in the world" (Commission, 2001a). Following up on this invitation, the Commission appointed a high-level Advisory Group, known by the name of its chairman as the "Mandelkern Group". The report on better regulation, delivered by the group in November 2001, dealt exclusively with "regulation" in the sense of traditional, top-down legislation and argued for simplification, transparency and better implementation. The main reason for the proposed changes seems to be the impact regulation has on business activities and on competitiveness. On the governance side, the White Paper on Governance published by the Commission in 2001 clearly states that "the Commission will promote greater use of different policy tools (regulations, "framework directives", co-regulatory mechanisms)" (emphasis added) (Commission, 2001). The accent put on "new and more flexible regulatory approaches" is very much in line with the Lisbon strategy, in the sense that while traditional ways of regulating need to become more business-friendly, new approaches need to be devised and used, avoiding burdens to industry and favoring competitiveness and growth. The review of both Lisbon and the SDS confirmed the tendency towards de-regulation and soft methods of policy-making. Thus, "what emerged from the Lisbon mid-term review is that every new piece of legislation will be double-checked by the Commission to ensure that it does not impose unnecessary burdens on businesses, growth and job creation. Incentives and voluntary initiatives by businesses are therefore likely to be increasingly the key to the success of the achievement of the EU's sustainable development strategy, with less emphasis on legislation" (EurActiv, 2006). The text of the reviewed SDS itself clearly states that "the EU will seek to use the full range of policy instruments, whilst promoting the use of market based instruments for the flexibility they offer in meeting sustainable development objectives" (Commission, 2005). The overall picture that emerges is that, in order to achieve the Lisbon goals, measures that might affect business activities (and, as a consequence, growth and competitiveness) are to be avoided. "Working with the market" means, in fact, "not working against the market", which in turn means getting stakeholder to engage, on a voluntary basis, in the shaping and the application of soft methods of policy-making, rather than have top-down legislation imposed on them. Given that, despite their ambiguous relationship, Lisbon is for the moment conditioning the application of the SDS, environmental policy has been realigned in function of this change in the EU policymaking philosophy. As a result, policy initiatives following up on the SDS rely increasingly, if not exclusively, on voluntary instruments for their implementation.

Nonetheless, it is important to acknowledge that the move towards voluntary instruments in environmental policy-making did not start with Lisbon. The notion of "shared responsibility" of EU institutions, member states and stakeholders was actually first articulated in the 5th Environmental Action Programme in 1992, reiterated in its 1998 review and further consolidated in the 6th Environmental Action Programme adopted in 2002. Nevertheless, the debates on better regulation following Lisbon did impact on environmental policy-making in the sense that voluntary instruments 
become the preferred means of implementation for new, encompassing policy initiatives that originate directly in the SDS. It is the case, for instance, with Integrated Product Policy or with the directive on the eco-design of energy-using products.

IPP is a policy initiative set forth in a Commission Communication in 2003 meant to promote the integration of environmental concerns into all stages of a product life-cycle (from design to waste). It is based on five key principles, namely life-cycle thinking, working with the market, stakeholder involvement, continuous improvement and variety of instruments. For its implementation it relies on a mix of voluntary instruments, the choice of which is mostly left into the hands of producers. As for the recently adopted directive on the ecodesign requirements for energy using products ${ }^{2}$ is meant to contribute to the integration of life-cycle thinking into product design by improving the environmental performance of energy-using products. This is to be achieved either via the development of implementing measures (in comitology or standardisation) or via self-regulatory voluntary agreements concluded by the producers. If voluntary agreements are signed, then implementing measures are no longer developed, thus bringing the whole mechanism of the directive to a halt ${ }^{3}$.

Because of space limitations, this article will only deal, briefly, with the analysis of three voluntary instruments used in environmental policy-making that are an integral part of the IPP toolbox. It is important to take a close look at these instruments for several reasons. On the one hand, they are interesting examples of the multilevel dynamics in the EU system of governance. The instruments are designed at the EU level, implemented at the national/regional level. They imply strong stakeholder involvement at all levels, a strong public-private interplay both at the design and at the implementation stages of the policy process. On the other hand, despite the fact that their creation initially preceded Lisbon and the better regulation debates, their current reframing within new policy frameworks such as the above-mentioned IPP is a clear sign of the intention of the European Commission to rely increasingly on voluntary instruments.

In the Commission's own words, the EU Eco-label is "a voluntary scheme designed to encourage businesses to market products and services that are kinder to the environment and for European consumers - including public and private purchasers - to easily identify them" (European Commission website, 2005). It is a market-based instrument, meant to stimulate both the supply and the demand of greener products and is based on Regulation 880/92 (revised in 2000, Regulation 1980/2000).

From a stakeholder perspective, the EU Eco-label never had strong support from economic operators (producers, distributors, services and importers). A study conducted in 1998, by IEFE and ICEM-CEEM, identified a vicious circle that acts as the main barrier hindering the adoption of the EU Eco-label by companies: companies either do not know about the EU Eco-label or have not heard of success stories; consumers do not know the label and therefore do not ask for it; retailers hardly ever offer eco-labelled products because there are few of them; and because retailers do not promote such products the consumer does not know about them. Indeed, different studies carried out in several Member States also underline the poor level of consumer awareness of the label. Thus, for instance, the EU Eco-label is known by $1 \%$ of the consumers in Germany, $0,4 \%$ in Italy and $1,2 \%$ in Spain (EVER, 2005). The differentiated consumer response to the label leads to different marketing strategies: a Swedish paint producer for instance sells an Eco-labeled product in Sweden (where consumers are more aware of the label) and the very same product without the label in Belgium (interview Belgian Competent Body, April 19, 2005).

Figures seem to confirm the fact that the EU Eco-Label does not have many supporters in the market and is not very successful. Thus, criteria have been drafted for some 23 product groups (out of which 5 are under revision) and a further 5 product groups are under development. 224 licenses for the use of the logo have been awarded throughout the EU so far. These figures do not 
account for the differences among countries and product groups, which are highly imbalanced. Thus, only a few of the product groups account for most of the products labeled. In 2000, when only 15 product groups were developed, four of them (paints and varnishes, textile products, footwear, tissue paper) accounted for $85 \%$ of all products labeled. At the same time, $75 \%$ of the products labeled were concentrated in five countries. Nevertheless, success should not be judged on figures alone, as many people involved in the scheme both at the national and at EU level point to the indirect but important effects of the eco-label. Thus, for instance, a study carried out by AEAT in 2004 at the request of DG Environment identified a series of indirect uses of the eco-label criteria such as being used by other eco-label schemes, in calls for tender or as a basis for establishing fiscal measures to promote green products.

In addition to taking the indirect effects into account, a country-by-country analysis of the implementation of the EU Eco-labeling scheme would be needed to assess its success. Given that the national Competent Bodies are in charge of promoting the scheme and dealing with applications at the national level, the resources they have at their disposal, as well as the national legislative framework in which they work, are of extreme importance. The fact that it is up to national public authorities to render the scheme successful is also backed by the relative success of national eco-labeling schemes, such as the German Blue Angel (currently about 3800 products covered).

The EU scheme is scheduled for revision in 2006. There is no official position yet concerning the points that will be revised, as an assessment study is currently being developed by Bocconi University. Nevertheless, there are a few issues that will be discussed during the revision process and that point to current problems in the scheme. They mostly concern: a wider role for Competent Bodies and a possible merger of EMAS and Eco-label national Competent Bodies; legal personality and enhanced role for the EU Eco-labeling Board (EUEB); 4 the creation of a graded eco-label; mutual recognition of labels; and a thorough revision of the administrative set-up. An interim report on the revision of the scheme (jointly with EMAS) has been recently published. It summarizes part of the relevant literature and the preliminary conclusions of a series of interviews, but does not offer additional information as to the changes to be made to the scheme (EVER, 2005).

The EU Eco-labeling scheme is potentially a useful instrument for the purpose of IPP (the only concrete EU environmental product policy for the moment), with good coverage of the product life-cycle stages and multiple opportunities for stakeholder involvement. Nevertheless, a series of structural weaknesses such as the long criteria development process and the lack of response from the market render it highly inefficient. The on-going revision process might find remedies and transform the scheme into a valuable asset for the IPP instrument mix. However, this depends on the willingness of public authorities, at all levels, to commit to actively promoting the scheme and to rendering it more attractive to industry. This might break the vicious circle in which the EU scheme is currently stranded.

The EU Eco-Management and Audit Scheme (EMAS) is a voluntary management tool for all public and private sector organizations to evaluate, report and improve their environmental performance. Originally restricted to companies in industrial sectors, the scheme has been available since 1995 (Council Regulation 1836/93). Since 2001, it has been open to all organizations, both in the private and the public sectors (Regulation 761/2001).

The academic analyses of the scheme have shown that the most powerful participation leverage is the granting of regulatory relief (such as less frequent inspections) for registered companies. Nevertheless, the possibility and scope for a lighter regulatory touch are primarily nationallyspecific since they are related to the national regulatory traditions (Glachant et al., 2002). In Germany for instance, the granting of regulatory relief (Watzold et al., 2001) has led to the highest EMAS registration rates in the EU. Other motives detected in the literature for adopting 
EMAS are: continuing improvements in environmental performance, identifying weaknesses and potential uses of energy sources, motivating employees, improving the image of the company, increasing legal certainty, improving internal organization and documentation, detecting and minimizing environmental and liability risks and reducing specific environmental impacts (Morrow \& Rondinelli, 2002). According to a recent study commissioned by the European Commission within the review of the scheme, the main drivers pushing companies to register are mainly economic and strategic (competitive improvement, legal compliance, etc.), while environmental reasons such as the reduction of environmental impacts lag behind (EVER, 2005).

Nevertheless, except for Germany, which accounts for more than half of the total number of EMAS registered sites and organizations in the EU, the scheme does not seem to be too successful $(4,705$ sites in 3,275 EMAS registered organizations). This might be due to the capacity, and traditions, of member states to grant regulatory relief in exchange for EMAS registration, as shown by Glachant et al., but it could also be related to a series of other factors such as the nature of the Competent Bodies and the control capacity they possess (public authorities vs. chambers of commerce). Thus; for instance, the high number of EMAS-registered sites in Germany could be consistent with the fact that the Competent Bodies are in fact Chambers of Commerce, namely private bodies, as opposed to the public nature of the Competent Bodies in Belgium for instance. This distinction between private and public Bodies could entail different degrees of control and EMAS-registration based on looser or stricter interpretations of the Regulation.

One of the main barriers identified by companies and organizations to EMAS registration is that EMAS prescribes an obligation to improve, which in turns means yearly progress in each of the indicators. This seems to be a rather hard objective to achieve in practice. By contrast, ISO 14001 (the international technical standard for Environmental Management Systems) does not impose this obligation, but only seeks proof of the willingness to improve, which to a certain extent makes it more attractive to companies. Accordingly, organizations argue that progress should be assessed over a longer time span, to allow for short-term fluctuations. Another strong barrier, especially for SMEs, is the cost of implementation (mostly related to the cost of external consulting and verification). The list of barriers identified in the literature continues with the lack of customer interest and the lack of recognition and positive rewards by public institutions in certain cases (EVER, 2005).

Still, as in the case of the EU Eco-labeling scheme, success cannot be assessed based on the number of registered sites alone. EMAS also has important indirect effects, among which the most important is its role as an inspiration for other schemes. In the Region of Brussels for instance, EMAS was taken as a model by the regional public authorities when they created a new label for companies, "enterprise eco-dynamique". This label was created to respond to the needs of the service sector companies of the Region, for which EMAS was not the best suited tool.

Despite the mixed picture of EMAS throughout the EU, one thing seems to be clear: its success, or lack thereof, depends mostly on the attitude of public authorities (national or regional, according to the division of power in each Member State), on their willingness to provide regulatory relief for participating companies and on their pro-activeness. The latter can even lead to extreme applications, such as the compulsory nature of EMAS for certain enterprises and organizations ${ }^{5}$ in the Walloon Region in Belgium, which completely denies the voluntary nature of the instrument. Nevertheless, it appears that despite the fact that they are obliged to register for EMAS, the enterprises that do so appreciate the advantages of the system (legislative certainty, putting order into one's business, etc.) once they have implemented it. This only reinforces the extremely important role of public authorities in "pushing" for EMAS. The first step towards doing so is by setting an example by registering their own public sites. The Belgian government seems to be very much aware of this, as they have decided that all federal services are to implement EMAS by 2007. The high influence that the attitude of public authorities has on the number of EMAS registrations is confirmed by the studies on EMAS pilot projects. Thus, EMAS uptake in 
the Member States has been directly linked to the level of information and funding available at the national level. More precisely, the number of EMAS pilot projects was, at an early stage, directly proportional to the number of EMAS registrations (EVER, 2005).

The scheme is currently undergoing a review process, together with the EU Eco-label. There are no indications as to the reforms to be made, but they will most probably concern the relationship between EMAS and Corporate Social Responsibility, between EMAS and the EU Eco-label, and making EMAS global, among others. The Interim Report of the review process, recently published, limits itself to a review of the relevant literature and to a series of preliminary conclusions from interviews and does not provide additional information on the future reform measures.

According to the Commission Communication of 2002 on Environmental Agreements, ${ }^{6}$ environmental agreements at Community level are those by which stakeholders undertake to achieve pollution abatement, as defined in environmental law, or environmental objectives set out in Article 174 of the Treaty. Voluntary Environmental Agreements (VEAs), that can take the form of co-regulation, self-regulation or own initiative, are seen by the Commission as being part of a mix of policy instruments; an implementation tool rather than a means of deregulation. They have no specific Treaty basis but rely on a series of Communications from the Commission. ${ }^{7}$

At the EU level only a few VEAs have been concluded, the most well-known being the 1998 agreement between the European Commission and the European Car Manufacture Association (ACEA) aimed at reducing CO2 emissions from passenger cars. A new environmental agreement in the form of a unilateral industry self-commitment was proposed in 2004 (and endorsed by DG Enterprise) by a consortium of companies producing biodegradable and compostable polymers designed to ensure the observance of standard EN 1343 in the production of biodegradable and compostable polymers. If the application of the former has been heavily criticized by NGOs, the effectiveness of the latter cannot be assessed for the moment due to the short time elapsed since its conclusion. Nevertheless, its story is illustrative for the use of self-regulation at the EU level, especially keeping in mind the boost given to self-regulatory voluntary agreements by the EuP directive.

EN 13432 describes, in fact, when a product is "compostable"; a conclusion to be reached via a series of test methods. Based on the results of the tests, a label is awarded to products that qualify - it is, in practice, a quality label that shows compliance with standard EN 13432. A label can be protected (from a juridical point of view), while concepts such as "compostable" and "biodegradable" cannot be protected and have been used abusively by producers. The first purpose of the self-commitment is, therefore, to create the basis for and to protect a label indicating compostability. The industry federations behind the agreement are made up precisely of producers of bio-based and bio-degradable polymers, which in turn make up compostable packaging. Their market penetration at the moment is extremely limited and they are very active in promoting their products at national level. An EU-endorsed agreement ensures both free publicity (given that the Commission needs to publicize the agreement) and additional leverage power in national negotiations. As for DG Enterprise, who not only endorsed the agreement but had actually helped prepare it, it seems that it mainly wanted a VEA (the first one after the 2002 Communication) and took advantage of its working group on Renewable Raw Materials being out of work at a certain moment to serve as a negotiating forum for the agreement (interview, May 2005). This story mainly shows that for self-regulation to occur a pro-active industry is needed; industry seems to be pro-active mostly when it is made up of non-dominant market players (companies well established on the market generally resist any change in the status quo). The other lesson to be drawn from this case is that DG Enterprise and DG Environment have different understandings of what a VEA should be. DG Environment was not involved in the preparation of the self-commitment and now argues it would not have acknowledged it because it brings no added value in environmental terms (Interview DG Environment, April 7, 2005). On the other hand, DG Enterprise is not at peace with the definition of VEAs as proposed by the Commission 
in its Communications and is more in favor of voluntary initiatives and self commitments from industry (for which this particular agreement is an example) (Interview DG Enterprise, March $29,2005)$. Given the stress on self-regulation in the EuP Directive, it seems that for the moment it is the vision of DG Enterprise that prevailed.

Although only a limited number of VEAs were concluded at the EU level, both NGOs and the European Parliament have been extremely critical of the use of this instrument by the Commission for several reasons. It is argued that there is little evidence that environmental agreements are effective, that the existing control systems are based on self-monitoring and hence subjective and that negotiated agreements (when industry commits itself to a certain environmental performance while the government in return agrees to refrain from direct regulation in this issue area while the agreement is in effect) severely restrict the range of policy options for future governments. Besides, these agreements are often concluded in the absence of parliamentary control and without the participation of the public in the negotiations. Industry on the other hand, wants the agreements to retain as much flexibility as possible and is not too happy about publicizing negotiations and results.

Given the equally mixed balance of VEAs at national levels, not to mention the pretty somber picture at EU level, the appropriateness of this instrument for encompassing EU-level policy initiatives (e.g. IPP and EUP) needs to be questioned from at least one perspective. A clear and workable set of criteria should be identified and applied. The literature on environmental agreements is extremely rich in conditions for success that could be taken as an inspiration by policy-makers to turn VEAs into a workable instrument. The guidelines of the Commission are admirable on paper and some authors have even proposed taking them as criteria for both national and EUlevel agreements and developing a Europe-wide mechanism to monitor the implementation of the guidelines (Volpi \& Singer, 2002). In the absence of such mechanisms, it is hard to imagine what kind of VEAs the Commission envisages as implementation tools for IPP or the EuP directive. If it is EU-level VEAs that the Commission wants to promote, the question remains of whether they would be used as self-regulation or as co-regulation. Following the example of the EuP Directive it might seem that self-regulation is the way forward for EU-level agreements. Nevertheless, for self-regulation to happen industry would need to be pro-active, which does not seem to be the case so far, especially where there is no regulatory relief in exchange. If it is national-level VEAs that the Commission envisages, then a series of co-ordination mechanisms would be needed in order to ensure, for instance, that free market principles are not violated.

\section{Competitiveness and environmental policy: a successful experiment?}

The concern to work with the market and to achieve environmental improvement through voluntary measures tallies well with the overall Lisbon goals. It is thus no surprise that concerns regarding competitiveness have had an impact on EU environmental policy. Certain environmental policy initiatives (e.g. EUP and IPP) seek to achieve environmental goals through the use of different voluntary instruments. These voluntary instruments are concrete formats of how to involve private actors in a non-coercive, negotiated and pragmatic fashion for the pursuit of collective goals. It is thus of crucial importance to asses the results and consequences of the instruments.

Unfortunately, the results and track record of the discussed instruments does not appear very promising. Having seen where the EU Eco-label, EMAS and VEAs currently stand, one can not identify a considerable impact on markets. The numbers of awarded EU eco-labels, EMAS labels and European VEAs, all point at a very limited up-take by producers and/or organizations. Left to their own devices, markets do not seem to offer the incentives to producers to adopt the environmental instruments developed by the European Union. The costs involved in adopting the voluntary instruments outweigh the benefits for the vast majority of producers in the market. When markets do not offer the incentives, public authorities can create conditions that render 
the voluntary measures more appealing. In fact, in those countries where public authorities are willing and able to provide flanking measures (e.g. Germany, Belgium) the voluntary measures are more readily adopted.

The IPP and EUP policy initiatives suggest a mix of voluntary instruments to improve the environmental impacts of products. While acknowledging that self-standing instruments can not be expected to achieve significant behavioral change, both policies offer little guidance on how policy instruments should be mixed and how public authorities at different levels should coordinate their actions. The lack of clear guidelines or prescription and the overall ambiguity of the policies based on voluntary instruments seems to resemble closely what Matland (1995) coined as "experimental implementation". It concerns the implementation of a policy characterized by high ambiguity and low conflict, in which contextual conditions dominate the process and where outcomes largely depend on which actors are active and most involved. This is precisely what happens with IPP: there are no clear, staged or quantifiable goals and the European Commission only offers a list of voluntary instruments that could be used. Thus, decisions are actually taken during the implementation phase, which is largely left to initiative of private actors. Their involvement clearly depends on contextual factors such as perceived economic interest or gains in national regulatory systems and, therefore, cannot be expected to be uniform or constant. In this regard, it is possible that the IPP and EUP initiatives suffer the same fate as the discussed voluntary instruments, namely, a very limited up-take resulting in ineffective policy initiatives.

The heavy reliance on economic actors for the execution of environmental policies, which we find in the IPP and EUP initiatives, may trigger circular dynamics of responsibility shifting between levels of government. For instance, in IPP the target groups of the policy (producers, consumers and public authorities) and their respective roles present a division of labor in which producers are to drive and deliver the policy program. Public authorities are to generate a framework and the conditions for producers to come forward and to achieve the policy goals. Organizing persuasion and policy learning seems to be the main function of the European public authority in the IPP, rather than achievement of behavioral changes through constraining legislation or tax incentives. Confining the role of public authorities to that of a facilitator is not without consequence in a multi-level system. Member states facing regulatory competition in a common market and producer resistance to measures which could entail costs and competitive disadvantages, point to the EU as the relevant policy level for market correction. However, at the EU policy level direct and coercive intervention is largely discarded as an adequate or viable policy option. Instead IPP posits facilitation as the main governmental responsibility and it singles out producers as the actors that must achieve and deliver the market correction through the adoption of voluntary instruments. The uptake of which does not seem to be forthcoming. The shift from state to markets to establish collective decisions combined with the presence different policy levels can easily give rise to extensive responsibility and burden shifting and eventually to governance failures.

Matland's description of experimental implementation does include a positive side to ambiguity, namely that it can be seen as an opportunity to learn new means and new goals. Thus, the learning experience to which it might lead to could prove to be more important than a successful implementation outcome. Nevertheless, if learning is the main goal, then the process should not be constrained artificially and the objective of learning should be consciously acknowledged. None of these two conditions seems to be met in the case of IPP or EUP: the policies are not presented as being a learning exercise, which leads to high expectations from the part of stakeholders as concerns concrete results in its implementation. Moreover, national governments tend to adopt a "wait-and-see" attitude in the policy domains where EU undertakes initiatives, thereby in effect suspending further national policy developments.

Formulating and implementing public policy in a context of increased diversity, scale and interdependence presents public authorities with formidable cognitive and information requirements. Public authorities at national, and especially at supranational levels, often do 
not have the means to overcome the challenges of uncertainty and incomplete information. Hence, resorting to more "experimental" policy designs and involving stakeholders can provide information and support both are much needed assets in multilevel political systems. Voluntary instruments can constitute a solution to the problem of incomplete information and they may also reduce the probability of damaging conflict. However, experiments as well as voluntary instruments require significant and sometimes decisive public steering and sanctioning, without which experiments may fail to deliver.

\section{Notes}

1) This article grows out of many discussions I have had with Prof. Theo Jans (VUB); I am grateful for all the insights he provided me with and for the enriching discussions we had. Parts of this research have been conducted in the framework of the project "The Role of Public Authorities in Integrated Product Policy: Regulators or Coordinators?", funded by the Belgian Science Policy Office. I acknowledge both their generous support and the excellent work accomplished by the whole research team.

2) Directive 2005/32/EC of the EP and the Council establishing a framework for the setting of ecodesign requirements for energy-using products

3) For a full discussion of the EuP directive see Misonne (2005)

4) Currently, the process of criteria development takes on average two years, out of which at least six months are lost because of the internal decision-making mechanisms of the Commission. Criteria, once agreed on, need to be formalized through a Commission decision - an official document that has to go through all the stages of adoption within the institution (inter-service consultation, translations, etc). If the EUEB would be entrusted, as a body with legal personality, with the formal adoption of criteria, the whole process would be reduced.

5) In the Walloon Region EMAS is compulsory for public enterprises (such as water treatment plants, waste collection enterprises, etc) and for organizations that receive public subsidies.

6) $\operatorname{COM(2002)~} 412$ final "Communication on Environmental Agreements at Community Level - Within the Framework of the Action Plan on the Simplification and Improvement of the Regulatory Environment"

7) $\operatorname{COM}(1996) 561$ final "Communication on Environmental Agreements", COM(2002) 0278 final Communication Action plan "Simplifying and improving the regulatory environment", $\operatorname{COM}(2002) 0412$ final "Communication Environmental Agreements at Community Level Within the Framework of the Action Plan on the Simplification and Improvement of the Regulatory Environment"

8) The norm EN13432 defines biodegradability and compostability and is recommended in the Directive on Packaging and Packaging Waste 94/62/EC.

\section{Websites}

www.euractiv.com/en/innovation/relaunch-lisbon-strategy/article131891

http://europa.eu.int/comm/environment/ecolabel/index_en.htm

http://www.blaver-engel.de/englisch/navigation/body_blauer_engel.htm

\section{References}

AEAT in Confidence (2004) The Direct and Indirect Benefits of the European Ecolabel - Final Report, November 2004. On http://europa.eu.int/comm/environment/ecolabel/pdf/ market_study/benefitsfinalreport_1 104.pdf. 
Council of the European Union (2006) Renewed EU Sustainable Development Strategy, Brussels, 9.06.2006.

Delmas, M., Terlaak, A. (2001) A Framework for Analyzing Environmental Voluntary Agreements. California Management Review 43: 3, 44- 63.

European Commission (2001) European Governance. A White Paper, COM(2001) 428 final, Brussels, 25.07.2001.

European Commission (2005) Communication from the Commission to the Council and the European Parliament "On the review of the Sustainable Development Strategy. A Platform for Action, $\operatorname{COM}(2005) 658$ final, Brussels, 13.12.2005.

European Commission (2005a) Communication to the Spring European Council "Working together for growth and jobs. A new start for the Lisbon Strategy, COM(2005) 24, Brussels, 02.02.2005.

European Commission (2005b) Communication from the Commission to the Council and the European Parliament"Draft Declaration on Guiding Principles for Sustainable Development" $\operatorname{COM}(2005) 218$ final, Brussels, 25.05.2005.

European Environmental Bureau (2004). EEB Evaluation of the European Eco-label Criteria and Scheme. "What we wanted - what we got ... ». On http://www.eeb.org/activities/ product_policy/EEB-Ecolabel-evaluation-What-we-wanted-what-we-got-July2004.pdf.

European Environmental Bureau (2005) EEB position paper for the Spring Summit - 18 February 2005 "Lisbon" needs a strong environmental dimension.

EVER Study Interim Report (2005) On http://europa.eu.int/comm/environment/emas/pdf/ everinterimreport_en.pdf.

Glachant, M., Schucht, S., Bultmann, A., Watzold, W. (2002). Companies' Participation in EMAS: The Influence of the Public Regulator. Business Strategy and the Environment 11, 254266.

Golub, J. (ed.) (1998) New Instruments for Environmental Policy in the EU. (London: Routledge).

Grepperud, S. (2002) Voluntary environmental agreements: bargaining over more than emissions. European Journal of Political Economy 18, 545-559.

IEFE \& ICEM-CEEM. (1998) Project for the Promotion and Diffusion of the EU Eco-label in Italy and the Benelux. Final Report Submitted to the European Commission DG XI.E.4. On http:// europa.eu.int/comm/environment/ecolabel/pdf/market_study/bocconi.pdf.

Ingram, V. (1999) From sparring partners to bedfellows: joint approaches to environmental policy-making. European Environment 9, 41-48. 
Lyon, T., Maxwell, J. (2003) Self-regulation, taxation and public voluntary environmental agreements. Journal of Public Economics 87, 1453-1486.

Mandelkern Group on Better Regulation (2001) Final Report, 13.11.2001.

Matland, R. E. (1995) Synthesizing the implementation literature: the ambiguity-conflict model of policy implementation, Journal of Public Administration Research and Theory 5: 2, 145174.

Missonne, D. (2005) The Directive on Ecodesign, the way forward regarding IPP ?. ELNI review 2, 16-28.

Morrow, D., Rondinelli, D. (2002) Adopting Corporate Environmental Management Systems: Motivations and Results of ISO 14001 and EMAS Certification. European Management Journal 20: 2, 159-171.

OECD (1997) Voluntary approaches for environmental policy - an assessment. (Paris: OECD).

Pallemaerts, M., Azmanova, A. (2006) The European Union and Sustainable Development. Internal and External Dimensions. Brussels: VUB Press.

Pallemaerts, M. et al. (2006a) The role of public authorities in Integrated Product Policy: regulators or coordinators? Brussels: Belgian Science Policy.

Rousseau, C. et al. (2004) Label écologique européen: quels impacts sur les choix de consommation?. (Bruxelles: CRIOC).

Taylor Nelson Sofres Consulting (2001) Investigation of the market impacts and penetration of the European Eco-label over the years 1992-2000 and 2001-2004. Final Report. On http:// europa.eu.int/comm/environment/ecolabel/pdf/market_study/sofresoutlookphase1_1201. pdf.

ten Brink, P. (ed.) (2002) Voluntary Environmental Agreements. Process, practice and future use. (Sheffield: Greenleaf Publishing).

Vermeire, I. et al. (2003) Development and Implementation of Marketing Actions for the European Eco-Label in Belgium.

Watzold, F. et al. (2001) EMAS and Regulatory Relief in Europe: Lessons from National Experience. European Environment 11, 37-48.

WWF. Will voluntary agreements at EU level deliver on environmental objectives? Lessons from the agreement with the automotive industry. On http://www.uneptie.org/outreach/vi/ reports/wwf.pdf. 